\title{
Effects of oat bran, processed to different molecular weights of $\beta$-glucan, on plasma lipids and caecal formation of SCFA in mice
}

\author{
Tina Immerstrand ${ }^{1 *}$, Kristina E. Andersson ${ }^{2}$, Caroline Wange ${ }^{3}$, Ana Rascon $^{3}$, Per Hellstrand ${ }^{2}$, \\ Margareta Nyman ${ }^{1}$, Steve W. Cui ${ }^{4}$, Björn Bergenståhl ${ }^{5}$, Christian Trägårdh ${ }^{5}$ and Rickard Öste ${ }^{1,3}$ \\ ${ }^{1}$ Division of Applied Nutrition and Food Chemistry, Department of Food Technology, Engineering and Nutrition, Lund University, \\ P.O. Box 124, SE-221 00 Lund, Sweden \\ ${ }^{2}$ Department of Experimental Medical Science, Lund University, Lund, Sweden \\ ${ }^{3}$ Aventure AB, Scheelevägen 22, Lund, Sweden \\ ${ }^{4}$ Guelph Food Research Centre, Agriculture and Agri-Food Canada, Guelph, ON, Canada \\ ${ }^{5}$ Division of Food Technology, Department of Food Technology, Engineering and Nutrition, Lund University, Lund, Sweden
}

(Received 11 November 2009 - Revised 28 January 2010 - Accepted 1 February 2010 - First published online 25 March 2010)

In the present study, we evaluated the cholesterol-lowering effects of different oat bran (OB) preparations, differing regarding their peak molecular weight $\left(\mathrm{MW}_{\mathrm{p}}\right)$ of $\beta$-glucans $(2348,1311,241,56,21$ or $<10 \mathrm{kDa})$, in C57BL/6NCrl mice. The diets were designed to be atherogenic ( $0.8 \%$ cholesterol and $0.1 \%$ cholic acid), and they reflected the Western diet pattern (41\% energy fat). All OB preparations that were investigated significantly reduced plasma cholesterol when compared with a cellulose-containing control diet, regardless of the molecular weight of $\beta$-glucan. Moreover, the difference in viscous properties between the processed OB (from $0 \cdot 11$ to $17 \cdot 71 / \mathrm{g}$ ) did not appear to play a major role in the cholesterol-lowering properties. In addition, there was no correlation between the molecular weight of $\beta$-glucan and the amount of propionic acid formed in caecum. Interestingly, however, there was a significant correlation between the ratio of (propionic acid + butyric acid)/acetic acid and the $\mathrm{MW}_{\mathrm{p}}$ of $\beta$-glucans: the ratio increased with increasing molecular weight. The results of the present study suggest that the molecular weights and viscous properties of $\beta$-glucan in oat products may not be crucial parameters for their cholesterol-lowering effects.

Molecular weight: $\beta$-Glucan: Cholesterol: SCFA: Mice

The cholesterol-lowering effects of oats have been studied in both human subjects and animals since the beginning of the $1960 \mathrm{~s}$. This effect has mainly been ascribed to its content of the soluble fibre $\beta$-glucans, as $80 \%$ purified oat $\beta$-glucan has been shown to reduce cholesterol levels in hypercholesterolaemic human subjects $^{(1)}$. In 1997, the Food and Drug Administration approved a health claim for oat products based on soluble fibres from whole oats (i.e. oat bran (OB), oatmeal or rolled oats, and also whole-oat starch) after a review of thirty-seven clinical studies of the effect of oats on blood lipids ${ }^{(2)}$. Daily intake of a minimum of $3 \mathrm{~g}$ oat $\beta$-glucans was deemed necessary to cause a relevant reduction in cholesterol levels. Health claims for $\beta$-glucans from barley have subsequently been approved ${ }^{(3)}$. However, it is not completely understood what molecular structure the $\beta$-glucans should exhibit to be physiologically active or to what extent other cereal components, e.g. lipids, antioxidants and other types of dietary fibres, contribute to the effect.

Cereal $\beta$-glucans are linear polysaccharides that are present in the cell walls, and they are found in oats, barley, wheat and rye. They are composed of a chain of glucose units connected by $\beta-(1-4)$ and $\beta-(1-3)$ linkages. Apart from the $\beta$-glucan content, the repeating pattern of these linkages varies between cereals; it has been shown to affect the solubility and gelation properties $^{(4)}$. Different processing treatments of oats, e.g. bread baking $^{(5)}$ or repetitive freeze-thaw treatments ${ }^{(6)}$, have been shown to change the molecular weight and/or the solubility of $\beta$-glucans. Such changes may possibly affect the cholesterol-lowering effects, although our knowledge about the relevant parameters is incomplete. Both the viscosity and the concentration of $\beta$-glucans after in vitro digestion have been reported to have a significant influence on the glucose response after a meal ${ }^{(6)}$. Another clinical study of various oat $\beta$-glucans found that there was a linear correlation between the change in plasma glucose after a meal and the viscosity of the drink consumed ${ }^{(7)}$. In contrast to the abovementioned reports, studies of $\beta$-glucans of different molecular weights have shown that there is no difference in cholesterollowering effects either in animal models ${ }^{(8,9)}$ or in human subjects ${ }^{(10)}$. In order to optimise the cholesterol-lowering

Abbreviations: $\mathrm{MW}_{\mathrm{p}}$, peak molecular weight; OB, oat bran; POB, processed OB.

* Corresponding author: Tina Immerstrand, fax +46 46222 4532, email tina.immerstrand@appliednutrition.lth.se 
effects of oat products, a more detailed understanding of the importance of different physico-chemical properties of $\beta$-glucans (including molecular weight) is needed.

Gallaher et $a l .{ }^{(11)}$ investigated the cholesterol-reducing effects of hydroxypropyl methylcellulose in hamsters, and found a correlation between plasma cholesterol levels and the viscosity of the intestinal contents. Isolated $\beta$-glucan ( $80 \%$ pure) and rolled oats have been shown to increase the viscosity of the small intestinal contents in rats in comparison to rats fed a diet containing cellulose ${ }^{(12)}$. One might therefore expect that the viscous properties of oat products would play a fundamental role in their biological activity.

It has been suggested that propionate, one of the SCFA produced when $\beta$-glucans are fermented in the large intestine, can reduce hepatic cholesterol synthesis ${ }^{(13)}$. Such effects of intestinal fermentation of $\beta$-glucans may thus contribute to their cholesterol-lowering effects. However, to our knowledge, the effect of the molecular weight of $\beta$-glucan on the formation of SCFA has not been investigated.

Human trials of oat products are time-consuming and costly to perform. Thus, an animal model (e.g. mice) can often be a suitable tool for screening of new potential food ingredients or to investigate the mechanisms of action. We have recently demonstrated that cholesterol-lowering effects of oats can be evaluated in $\mathrm{C} 57 \mathrm{BL} / 6 \mathrm{NCrl}$ mice that are fed an atherogenic $\operatorname{diet}^{(14)}$. This mouse model was used in the present study, where the main objective was to investigate the roles that molecular weight and viscous properties of oat $\beta$-glucan play in the cholesterol-lowering effects of oat products. We also wanted to evaluate their effect on the lipoprotein pattern and on TAG, and their effect on the formation of SCFA in the caecum.

\section{Materials and methods}

\section{Experimental protocol}

A control experiment was performed to investigate whether processing of $\mathrm{OB}$, wet milled and amylase treated but without $\beta$-glucanase treatment, affects its cholesterol-lowering properties. After confirming that there was no difference in cholesterol-reducing effects between processed OB (POB; $1311 \mathrm{kDa}$ ) and $\mathrm{OB}$, or in gain in body weight, feed intake and dry faeces output (data not shown), two separate experiments were performed to evaluate how different molecular weights of $\beta$-glucans in the POB preparations affect plasma cholesterol and production of SFCA in the caecum. In the first experiment, we compared the effect of POB $(1311 \mathrm{kDa})$ used in the control experiment with the effect of three other $\beta$-glucanase-treated POB $(241,56$ and $21 \mathrm{kDa})$. In the second experiment, the effect of an additional POB with $\beta$-glucans of even lower peak molecular weight $\left(\mathrm{MW}_{\mathrm{p}}\right.$; $<10 \mathrm{kDa}$ ) was compared with the effect of untreated OB.

\section{Animals}

Female C57BL/6NCrl mice were purchased from Charles River Laboratories (Sulzfeld, Germany). All mice were fed normal chow (R34 rodent chow; Lactamin, Sweden) during an adaptation period of 2 weeks. At 10-12 weeks of age (body weight $17-21 \mathrm{~g}$ ), mice were randomly divided into experimental groups, and were housed together in cages with ten animals per cage. The mice were kept in a temperature-controlled room with a 12-h light cycle environment, and they had free access to food and water. All experiments were approved by the Malmö/Lund regional ethical committee for laboratory animals. The animals ( $n$ 110) tolerated the studies well except for one animal (in Expt 2, fed control diet) that had symptoms of illness and was withdrawn from the study. After 4 weeks on the experimental diet, the mice were killed by cervical dislocation, and the caecal tissue and contents were collected.

\section{Diets}

To induce hypercholesterolaemia, an atherogenic diet $(0.8 \%$ cholesterol and $0.1 \%$ cholic acid) was designed, which reflected the Western diet with about $41 \%$ energy fat, $16 \%$ energy protein and $43 \%$ energy carbohydrates (Table 1). The different diets were produced in our laboratory from a premix purchased from Research Diets, Inc. (New Brunswick, NJ, USA), in the same way as we have described previously $^{(14)}$. During preparation of the diets, we assumed that all ingredients were dry, without correcting for traces of water.

In Expt 2, the diet formulae were adjusted to fit the nutrient composition of a new batch of OB (Table 2), in the same way as done when we designed the diets used in the initial control experiment and Expt 1 (Table 1). The experimental diets were fed as powders.

Table 1. Formulation of the atherogenic diets ( $\mathrm{g} / \mathrm{kg}$ diet $)^{\star}$

\begin{tabular}{|c|c|c|}
\hline Ingredients & Control diet & OB or POB diet $†$ \\
\hline Casein, 80 mesh $\ddagger$ & 200 & 146 \\
\hline DL-Met & 3 & 4.5 \\
\hline Maize starch & 272 & 133 \\
\hline Maltodextrin & 100 & 100 \\
\hline Sucrose & 100 & 94 \\
\hline Cellulose & 44 & 0 \\
\hline Butter, anhydrous\| & 200 & 176 \\
\hline Maize oil & 10 & 10 \\
\hline Mineral mix S10026 & 10 & 10 \\
\hline Calcium phosphate & 13 & 13 \\
\hline Calcium carbonate & $5 \cdot 5$ & $5 \cdot 5$ \\
\hline Potassium citrate $\cdot 1 \mathrm{H}_{2} \mathrm{O}$ & $16 \cdot 5$ & $16 \cdot 5$ \\
\hline Vitamin mix V10001§ & 10 & 10 \\
\hline Choline bitartrate & 2 & 2 \\
\hline Cholesterol\| & $7 \cdot 54$ & $7 \cdot 59$ \\
\hline Sodium cholate & 1 & 1 \\
\hline OB or POBף & 0 & 270 \\
\hline \multicolumn{3}{|l|}{ Nutritional composition } \\
\hline Digestible carbohydrates & 482 & $464-483$ \\
\hline Fat & 210 & $210-212$ \\
\hline Protein & 176 & $176-193$ \\
\hline Total dietary fibre & 44 & $41-46$ \\
\hline Oat $\beta$-glucan & 0 & $19-23$ \\
\hline Total energy content (kJ/g diet) & 19 & 19 \\
\hline
\end{tabular}

$\mathrm{OB}$, oat bran; $\mathrm{POB}$, processed $\mathrm{OB}$

${ }^{*}$ All values are expressed in fresh weight.

†POB (produced from OB) with $\beta$-glucan of different peak molecular weights. $\ddagger$ Casein is $88 \%$ protein.

$\S$ Containing $97.8 \%$ sucrose.

II Anhydrous butter has $230 \mathrm{mg}$ cholesterol $/ 100 \mathrm{~g}$. To compensate for this, extra cholesterol was added so that total amount of cholesterol in all diets was $8 \mathrm{~g} / \mathrm{kg}$ diet.

ๆ Dry-milled OB (Avena sativa, cv. Sang b 1008596) or dry-milled POB, both $<0.8 \mathrm{~mm}$. The nutritional composion of $\mathrm{OB}$ and $\mathrm{POB}$ is illustrated in Table 2, and it explains the range in nutritional compositon of the $\mathrm{OB}$ diet and the $\mathrm{POB}$ diets. 
Table 2. Nutrient content of experimental processed oat bran $(\mathrm{POB})^{\star}$ products and the oat bran $(\mathrm{OB}) \dagger$ used as a starting material $(\mathrm{g} / 100 \mathrm{~g}) \ddagger$

\begin{tabular}{|c|c|c|c|c|c|c|c|}
\hline \multirow[b]{2}{*}{ Nutrient } & \multicolumn{5}{|c|}{ Expt 1} & \multicolumn{2}{|c|}{ Expt 2} \\
\hline & $\begin{array}{c}\mathrm{OB} \\
(1800 \mathrm{kDa}) \S\end{array}$ & $\begin{array}{c}\text { POB } \\
(1311 \mathrm{kDa})\end{array}$ & $\begin{array}{c}\mathrm{POB} \\
(241 \mathrm{kDa})\end{array}$ & $\begin{array}{c}\mathrm{POB} \\
(56 \mathrm{kDa})\end{array}$ & $\begin{array}{c}\mathrm{POB} \\
(21 \mathrm{kDa})\end{array}$ & $\begin{array}{c}\mathrm{OB} \\
(2348 \mathrm{kDa}) \|\end{array}$ & $\begin{array}{c}\mathrm{POB} \\
(<10 \mathrm{kDa})\end{array}$ \\
\hline Fat & 8.9 & $9 \cdot 3$ & 9.4 & $9 \cdot 1$ & $9 \cdot 6$ & 9.5 & $9 \cdot 8$ \\
\hline Protein & 18 & 24 & 24 & 24 & 24 & $19 \cdot 7$ & $19 \cdot 1$ \\
\hline Maltose & ND & 28 & 22 & 25 & 28 & ND & 27 \\
\hline Maltotriose & ND & 2.5 & 2.5 & $2 \cdot 2$ & $2 \cdot 7$ & ND & 2.9 \\
\hline Sucrose & $2 \cdot 2$ & 1.4 & $1 \cdot 1$ & 1.5 & $1 \cdot 7$ & $1 \cdot 2$ & 0.7 \\
\hline Glucose & ND & 0.0 & $2 \cdot 1$ & 0.0 & 0.0 & ND & 0.2 \\
\hline Total dietary fibre & 16 & 17 & 15 & 15 & 17 & 16 & 8.59 \\
\hline Whereof $\beta$-glucan & $7 \cdot 2$ & $8 \cdot 1$ & $8 \cdot 0$ & $8 \cdot 0$ & 8.4 & 7.5 & $6 \cdot 8$ \\
\hline Ash & 3.4 & $2 \cdot 6$ & $2 \cdot 6$ & $2 \cdot 8$ & 3.0 & $2 \cdot 9$ & 3.0 \\
\hline Digestible carbohydrates ${ }^{* *}$ & 54 & 47 & 49 & 50 & 47 & 52 & 609 \\
\hline
\end{tabular}

ND, not determined.

${ }^{*} \mathrm{POB}$ (produced from $\mathrm{OB}$ ) with $\beta$-glucan of different peak molecular weights.

†OB used as a starting material for the production of POB (see Materials and methods).

$\ddagger$ All values are based on DM.

$\S$ Avena sativa (cv. Sang), produced in 2007 by Lantmännen.

$\|$ A. sativa (cv. $43 \%$ Sang, $10 \%$ Kerstin and $47 \%$ mixed oats containing Belinda in large part); produced in 2008 by Lantmännen.

I The deviation of total dietary fibre and consequently total carbohydrates between POB $(<10 \mathrm{kDa})$ and OB $(2348 \mathrm{kDa})$ was most probably a consequence of the method used for the total dietary fibre analysis, which is based on an enzymatic digestion of starch and protein followed by precipitation of fibre with $80 \%$ ethanol ${ }^{(22)}$. However, fibres of less than ten to twenty monomers are not expected to be quantitatively precipitated.

${ }^{\star}$ Calculated by difference: 100 - protein - fat - ash - dietary fibre (for example, starch or minor sugars).

\section{Processing of oat bran}

Two batches of $\mathrm{OB}$ were used in the different experiments in mice; they were produced in the same mill (Lantmännen $\mathrm{AB}$, Järna, Sweden) but from different cultivation varieties of oats. The nutrient compositions of the two $\mathrm{OB}$ were similar (Table 2), and both were used as starting materials to produce five POB products that would differ only with respect to the molecular weights of $\beta$-glucans. In the initial control experiment and in Expt 1 (performed in 2008), we used OB based on a Swedish variety of oats named 'Sang' (produced in 2007, batch 1008596). In Expt 2 (performed in 2009), the OB used was based on a mixture of Swedish oat varieties: $43 \%$ Sang, $10 \%$ Kerstin and $47 \%$ mixed oats, mainly Belinda (produced in 2008, batch 1047749). This change was for agricultural reasons. However, we did not see any significant difference in the present results related to the source of the OB (Table 2 and Fig. 2).

Four POB products were produced essentially as described by Triantafyllou Oste ${ }^{(15)}$, and were treated with different amounts of $\beta$-glucanase from Aspergillus sp. (Biocon, Barcelona, Spain) to obtain different molecular weights of $\beta$-glucan. One of the batches was produced without the addition of $\beta$-glucanase for comparison with untreated OB. An additional, fifth $\mathrm{POB}$ product was produced in the same way except that in the $\beta$-glucanase step, excess amounts of a $\beta$-glucanase from Trichoderma longibrachiatum (Biocon) were used in addition to the $\beta$-glucanase from Aspergillus sp. The five products were obtained from OATLY AB (Landskrona, Sweden) as liquid suspensions. Before freeze-drying, a solution of maltodextrin (1:3 in water) was added to the liquid suspension to a final concentration of $19 \%$ in an attempt to prevent the formation of insoluble complex that would remain undissolved during the passage through the intestine in vivo. The mixture of $\mathrm{OB}$ and maltodextrin was placed on trays and stored at $-20^{\circ} \mathrm{C}$ before freeze-drying. DM and minor sugar components were analysed in all suspensions before mixing with maltodextrin.
The freeze-drying was kept constant at $-20^{\circ} \mathrm{C}$ for $162 \mathrm{~h}$, and the temperature was then raised to $+5^{\circ} \mathrm{C}$ (at $4^{\circ} \mathrm{C}$ per h; Labconco, Ninolab, Upplands Väsby, Sweden). The freezedried materials were dry milled to a particle size of less than $0.8 \mathrm{~mm}$ (Laboratory Mill 120; Perten Instruments, Huddinge, Sweden).

\section{Analysis of $\beta$-glucan in oat products}

Samples for molecular weight determination of $\beta$-glucan were extracted and analysed as described previously ${ }^{(16)}$. The POB samples were not extracted with ethanol before extraction with $0 \cdot 1 \mathrm{M}-\mathrm{NaOH}$ since the $\beta$-glucanases were assumed to be inactivated by processing. This was confirmed by comparing two samples with and without an ethanol extraction; the results showed that the molecular weights were the same in both cases.

The total $\beta$-glucan content of solid materials and liquid samples from viscosity measurements were determined by using a kit, following an enzymatic assay method for mixed linkage $\beta$-glucans ${ }^{(17)}$.

\section{Viscosity measurements}

The freeze-dried POB products were solubilised in deionised water for $1 \mathrm{~h}$ at room temperature under agitation with a magnetic stirrer (approximately $2.8 \mathrm{~g}$ POB per $28 \mathrm{~g}$ water). At least two replicates were made for each $\mathrm{POB}$ product. The samples were centrifuged at $15000 \mathrm{~g}$ for $10 \mathrm{~min}$, after which the amount of the supernatant was weighed. In order to determine the percentage of solubilised DM and $\beta$-glucan, a small aliquot of supernatant was taken and stored at $-20^{\circ} \mathrm{C}$ until the analysis was done. The viscosity of the supernatant was measured with a stress-controlled rheometer (StressTech, Reologica, Sweden) with a concentric cylinder (25 mm diameter: $\mathrm{CC} 25)$ at room temperature. 
Solutions with different sucrose concentrations were used to verify the method. In order to operate within a Newtonian region, the supernatant obtained from POB (1311 kDa) was diluted 1:1 with deionised water before the measurement of viscosity. Different shear stresses were used to provide a range of shear rate from 5 to 50 per s.

\section{Analysis of nutrient composition}

Protein content was determined with a Kjeltec System 1003 (Tecator AB, Höganäs, Sweden) or with a carbon/nitrogen analyser (Vario Max CN, Elementar Analysensysteme $\mathrm{GmbH}$, Hanau, Germany). Crude oat protein was calculated as nitrogen content $\times 6 \cdot 25$. Fat content was determined using the conventional styrene - butadiene rubber solvent extraction method based on the work of Schmid ${ }^{(18)}$, Bondzynski ${ }^{(19)}$ and Ratzlaff ${ }^{(20)}$, involving a gravimetric extraction in diethyl ether and petroleum ether $\left(40-60^{\circ} \mathrm{C}, 1: 1\right)$ after hydrolysis in $7.7 \mathrm{M}-\mathrm{HCl}$ and ethanol for $1 \mathrm{~h}$ at $75^{\circ} \mathrm{C}$. The content of total dietary fibre in the $\mathrm{OB}$ samples was determined by Eurofins Foods (Lidköping, Sweden) according to the Association of Official Analytical Chemists (985.29) method of Prosky et $a{ }^{(21)}$, whereas total dietary fibre in POB products was analysed according to the method of Asp et al. ${ }^{(22)}$. Both methods are gravimetric, and are based on the enzymatic digestion of starch and proteins followed by precipitation of the fibre with ethanol. These methods have shown good agreements $^{(23)}$. The sugar analysis of liquid suspensions was performed by means of HPLC using a Zorbax carbohydrate analysis column $(4.6 \times 150 \mathrm{~mm})$ from Agilent Technologies, Inc. (Santa Clara, CA, USA); elution was done with acrylonitrile $-\mathrm{H}_{2} \mathrm{O}(63: 37)$ at a flow rate of $1 \mathrm{ml} / \mathrm{min}$ and at $35^{\circ} \mathrm{C}$. Moisture content was determined by drying the samples for $15 \mathrm{~h}$ at $105^{\circ} \mathrm{C}$, whereupon the DM that remained was weighed after cooling in a desiccator for $1 \mathrm{~h}$.

\section{Plasma cholesterol, TAG and lipoproteins}

At baseline and after 4 weeks, blood samples were collected after 4-h fasting ${ }^{(14)}$. Total plasma cholesterol and TAG were determined with Infinity cholesterol/TAG liquid stable reagent (Thermo Trace, Noble Park, Vic, Australia). Plasma lipoproteins were electrophoretically separated in agarose gels in barbital buffer according to the method of Noble ${ }^{(24)}$. The gels were stained with Sudan black, and densitometric scanning (BioRad GS 800 Calibrated Densitometer and Quantity One quantitation software; BioRad, Hemel Hempstead, Herts, UK) of the intensity of the bands revealed the relative lipid distribution between LDL + VLDL $v$. HDL. Data are reported as $(\mathrm{LDL}+\mathrm{VLDL}) /(\mathrm{HDL}+\mathrm{LDL}+\mathrm{VLDL}) \times 100$. The percentage given for the lipoproteins reflects the lipid distribution among lipoproteins (since Sudan black stains cholesterol, TAG and phospholipids) and it does not exactly correspond to HDL- and LDL-cholesterol.

\section{Caecum}

The caecum was removed and weighed. The contents were transferred to a sterile tube and stored at $-80^{\circ} \mathrm{C}$ until analysis

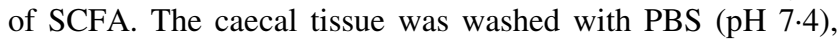
dried between layers of filter paper and weighed. Caecal content was calculated as the weight of the full caecum minus that of caecal tissue.

\section{$S C F A$}

SCFA (i.e. acetic, propionic, butyric, isovaleric, valeric, caproic and heptanoic acids) in the caecal content were analysed using a GLC method ${ }^{(25)}$. A sample of caecal content $(0.1 \mathrm{~g})$ was mixed with $1 \mathrm{ml}$ of a solution containing $0.25 \mathrm{M}-\mathrm{HCl}$ (to protonise SCFA) and $1 \mathrm{mM}$-2-ethylbutyric acid (as an internal standard). The sample was homogenised for 1 min with an Ultra Turrax T25 basic (IKA-WERKE, Staufen, Germany), and then was centrifuged (MSE Super Minor, Hugo Tillquist AB, Solna, Sweden). Two hundred microlitres of the supernatant were transferred to a microinsert bottle, and were injected onto a fused-silica capillary column (DB-FFAP 125-3237; J\&W Scientific, Folsom, CA, USA; Agilent Technologies Inc.). Caecal pools ( $\mu \mathrm{mol})$ of the different SCFA were calculated as the concentration of each acid ( $\mu \mathrm{mol} / \mathrm{g}$ caecal content) multiplied by the caecal content. The total SCFA pool was determined as the sum of SCFA in $\mu$ mol per caecal content, and the proportions of SCFA were determined as the ratio between the amount of acid $(\mu \mathrm{mol})$ per caecal content and the total SCFA pool.

\section{Calculations and statistical evaluation}

For calculations of the nutrient composition of POB products, the results were corrected for the $19 \%$ of maltodextrin by dividing the values by a factor of 0.81 .

The concentration-normalised viscosity was calculated as

$$
\frac{\eta_{\mathrm{sp}}}{c}=\left(\eta_{\mathrm{r}}-1\right) \times \frac{1}{c}=\frac{\eta_{\mathrm{s}}-\eta_{0}}{\eta_{0}} \times \frac{1}{c} \quad(1 / \mathrm{g}),
$$

where $\eta_{\mathrm{sp}}$ is the specific viscosity; $\eta_{\mathrm{r}}$ is the relative viscosity $\left(\eta_{\mathrm{s}} / \eta_{0}\right) ; \eta_{\mathrm{s}}$ is the viscosity of the solution containing the solute (i.e. the $\beta$-glucan in the present study); $\eta_{0}$ is the viscosity in the absence of the solute and $c$ is the concentration of the solute. The concentration of $\beta$-glucan in the solution was converted from weight percentage to $\mathrm{g} / \mathrm{l}$ using the corresponding density for sucrose solutions.

Data were analysed using the Minitab software package version 14.0 (Minitab, Inc., State College, PA, USA). Unless otherwise stated, results are expressed as means with their standard errors. Outliers were identified as samples deviating from the third quartile with more than $150 \%$ of the interquartile range. The Anderson-Darling test was used to determine the normality of the measurements, where $P<0.05$ rejects the null hypothesis that the data are normally distributed. For normally distributed data, one-way ANOVA was used for multiple comparisons (using the general linear model procedure), where Tukey's test for pairwise comparisons of means was used for the significance of difference $(P<0 \cdot 05)$. Two sets of data for SCFA were not normally distributed, and therefore median values were calculated and percentiles were presented (Table 5). The non-parametric Kruskal-Wallis test was performed to compare the median values between the groups based on the variance by ranks ${ }^{(26)}$. 


\section{Results}

Nutrient content of experimental products

The analysis of nutrient content confirmed that the nutrient composition of the $\mathrm{POB}$ products was roughly equal to what was obtained for $\mathrm{OB}$, which was used as a starting material (Table 2). A somewhat greater variation in protein content was seen $(18-24 \%)$ and consequently also in the content of digestible carbohydrates (46-53\%). There were no significant differences in the levels of minor sugars (i.e. sucrose, maltotriose, maltose and glucose) between the POB products. The total dietary fibre content measured was clearly lower in POB $(<10 \mathrm{kDa})$ than in the starting material (i.e. OB). This was most probably a consequence of the method used for the total dietary fibre analysis, which is based on an enzymatic digestion of starch and protein followed by precipitation of fibre with $80 \%$ ethanol as described by Asp et al. ${ }^{(22)}$. Following this method, fibre of less than ten to twenty monomers are not expected to be quantitatively precipitated. Thus, a significant amount, approximately $50 \%$ (8.5/16, see Table 2), of the dietary fibre that is present should be composed of less than ten to twenty monomers.

\section{Physico-chemical properties of processed oat bran}

The solubility of the $\beta$-glucans in the POB products after a standardised dissolving procedure of the $\beta$-glucans in the POB products is presented in Fig. 1(A). There were small differences in the amount of solubilised DM (Fig. 1(B)). Generally, $\beta$-glucans from products with low molecular weights dissolve to a greater extent than those from products with high molecular weights.

The viscosity of the particle-free supernatant of each product was determined. From the results on viscosity and the $\beta$-glucan concentrations, the concentration-normalised viscosity was estimated to compare the thickening efficiency of the different degradation levels of $\beta$-glucans. The concentration-normalised viscosity ranged from $1 \cdot 1$ for POB $<10 \mathrm{kDa}$ to $17 \cdot 7 \mathrm{l} / \mathrm{g}$ for POB of $1311 \mathrm{kDa}$ (Fig. 1(C)). Solubilisation of dry-milled $\mathrm{OB}$ in deionised water, by using the same conditions as for the POB, resulted in approximately $23 \%$ solubilised $\beta$-glucan and $5.7 \%$ solubilised DM.

The $\mathrm{MW}_{\mathrm{p}}$ value of $\beta$-glucan from OB based on 'Sang' oats was determined to be approximately 1800 (SEM 17) kDa, whereas of $\beta$-glucan from for OB based on $43 \%$ Sang was 2348 (SEM 25) kDa (means with their standard errors for duplicate samples). $\mathrm{MW}_{\mathrm{p}}$ values for the different $\mathrm{POB}$ products were 1311 (SEM 12), 241 (SEM 5), 56 (SEM 0.0) and 21 (SEM $0 \cdot 2$ ), respectively (expressed in $\mathrm{kDa}$ as means with their standard errors for duplicate samples). The $\mathrm{MW}_{\mathrm{p}}$ value of $\beta$-glucan for $\mathrm{POB}$ product produced using the most extensive enzyme treatment was not determinable, as we obtained a low fluorescence intensity that was close to the background level. It is known that the fluorescing complex between $\beta$-glucan and calcofluor is only formed at molecular weights of $\beta$-glucan that are greater than approximately $10 \mathrm{kDa}^{(27)}$. The $\beta$-glucans present in the most extensively enzyme-treated $\mathrm{POB}$ were therefore most probably equal to or less than about $10 \mathrm{kDa}$, and thus we refer to this sample as $\mathrm{POB}<10 \mathrm{kDa}$.
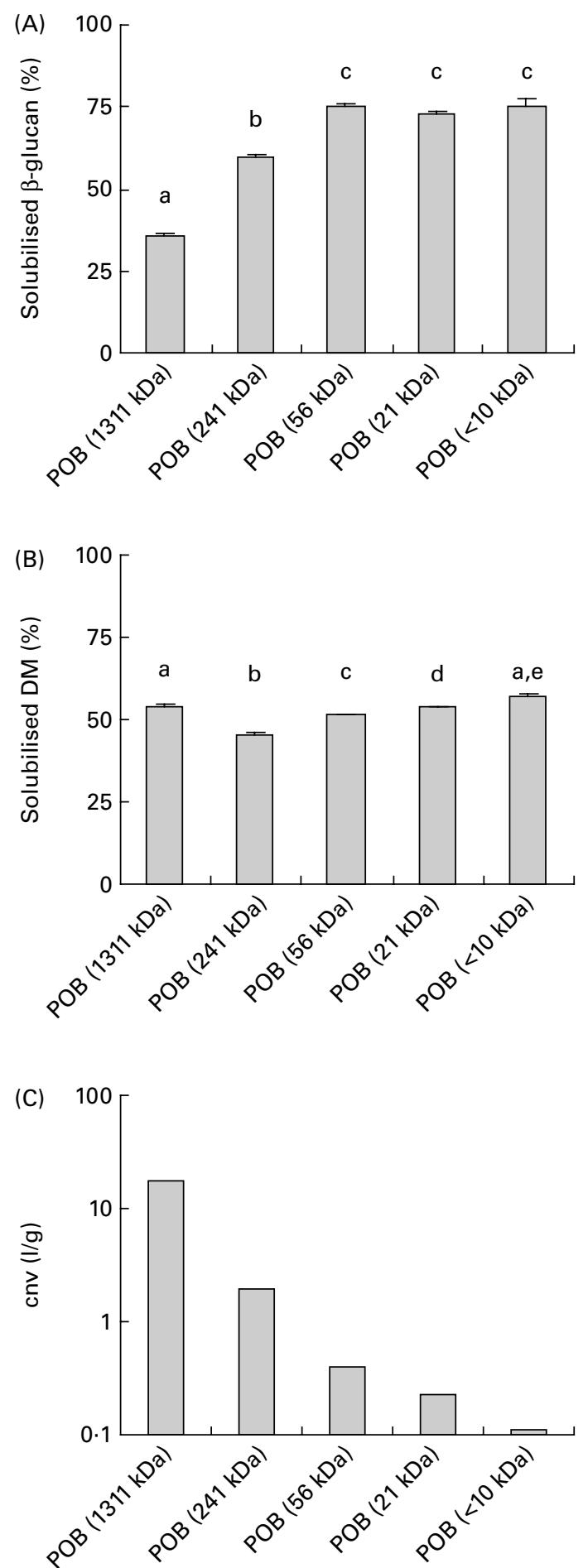

Fig. 1. Physico-chemical properties of processed oat bran (POB) samples with different $M W_{p}$ of $\beta$-glucans. The obtained level of water-soluble $\beta$-glucan from POB before viscosity measurement ((A), n 4-5). Solubilised DM from $\mathrm{POB}$ before viscosity measurement $((\mathrm{B}), n 6)$. Viscous properties of solubilised fractions of $\mathrm{POB}$ products, expressed as the concentration-normalised viscosity (cnv) which is equal to $\eta_{\mathrm{sp}} / c_{\beta \text {-glucan }}$ (see equation 1 ), where $c_{\beta \text {-glucan }}$ in solution was $1.4 \mathrm{~g} / \mathrm{l}$ for POB of $1311 \mathrm{kDa}, 5.5 \mathrm{~g} / \mathrm{l}$ for POB of $241 \mathrm{kDa}, 5.9 \mathrm{~g} / \mathrm{l}$ for POB of $56 \mathrm{kDa}, 5.8 \mathrm{~g} / \mathrm{l}$ for $\mathrm{POB}$ of $21 \mathrm{kDa}$ and $4.9 \mathrm{~g} / \mathrm{l}$ for $\mathrm{POB}<10 \mathrm{kDa}$, respectively $(C)$. The results are presented as mean values. Error bars in $(A)$ and $(B)$ show SEM. ${ }^{a, b, c, d, e}$ Mean values with unlike letters were significantly different $(P<0.05)$. 
Body weight, feed intake and faeces excretion

As in our previous study ${ }^{(14)}$, the body weight of all mice had increased during the 4 weeks on experimental diets, by an average of $2.8 \mathrm{~g}$ per mouse (pooled standard deviation $=0.95$ ).

The mice that were fed oat products generally increased significantly more in body weight than mice that were fed control diet, even though this varied somewhat between the experimental series. Moreover, feed intake and faecal output were similar in the different dietary groups (Table 3 ).

\section{Plasma cholesterol, lipoproteins and TAG}

Distribution plots representing the baseline and the 4-week levels of plasma cholesterol for all dietary groups of mice in each experiment revealed one outlier, which was excluded from further analysis. This mouse belonged to the control group in Expt 2, and had unusually high plasma cholesterol $(3.1 \mathrm{mmol} / \mathrm{l})$ at baseline, which became reduced by $0.15 \mathrm{mmol} / \mathrm{l}$ after 4 weeks on atherogenic diet.

In the first experiment, we found that all POB products, with $\beta$-glucans with different $\mathrm{MW}_{\mathrm{p}}$ values $(1311,241,56$ and $21 \mathrm{kDa}$ ), lowered plasma cholesterol equally (Fig. 2(A)). In an attempt to reveal a loss in efficiency by further reduction of molecular weight, we prepared another batch of POB with an $\mathrm{MW}_{\mathrm{p}}<10 \mathrm{kDa}$ (see Results: physico-chemical properties). However, the cholesterol-lowering effects of this product were also not significantly different from those of the unprocessed OB (Fig. 2(B)).

Four weeks on atherogenic diet induced a prominent shift of the lipoprotein profile, where the relative proportion of LDL + VLDL was approximately doubled. No statistically significant reduction in the proportion of LDL + VLDL was found after the addition of OB or any of the POB to the diet (Table 4). Mean TAG levels in Expt 1 were $0.52 \mathrm{mmol} / \mathrm{l}$ in control mice after 4 weeks, and they were not significantly affected by the oat products (data not shown), which is in line with the results of our previous study ${ }^{(14)}$.
Caecal content, caecal tissue weight and formation of SCFA

Weight of caecal tissue and the distribution of SCFA in the contents are given in Table 5. Mice fed POB with the highest $\mathrm{MW}_{\mathrm{p}}$ value of $\beta$-glucan $(1311 \mathrm{kDa})$ had higher caecal content than the control group $(P<0 \cdot 01)$. The weight of caecal tissue was higher for mice fed $\mathrm{POB}$ with a low $\mathrm{MW}_{\mathrm{p}}$ value, i.e. $21 \mathrm{kDa}(P<0 \cdot 01)$ and $56 \mathrm{kDa}(P<0 \cdot 05)$.

The total pool of caecal SCFA was higher $(P<0 \cdot 05)$ for mice that were fed POB with an $\mathrm{MW}_{\mathrm{p}}$ value of 1311 or $21 \mathrm{kDa}$ than for mice that were fed the control diet. Acetic acid was the predominant SCFA in all groups, followed by propionic acid and butyric acid. The mean ratio between these three acids was 64:23:13. The caecal pool of propionic acid was higher $(P<0.05)$ for all POB groups than for the control group $(2 \cdot 6-3.3$ v. $1.4 \mu \mathrm{mol}$, respectively). Butyric acid, on the other hand, was formed in higher amounts at the high $\mathrm{MW}_{\mathrm{p}}$ value $(P<0 \cdot 01)$ and low $\mathrm{MW}_{\mathrm{p}}$ value $(P<0.05)$ compared with the control group.

The ratio of (propionic acid + butyric acid)/acetic acid was significantly higher in all POB groups than in the control group, and increased with the $\mathrm{MW}_{\mathrm{p}}$ of the $\beta$-glucans in the POB products (Table 6).

\section{Discussion}

Solubility, viscosity and molecular weight are physicochemical properties that have been suggested to play crucial roles in the beneficial health effects of $\beta$-glucans. It has been demonstrated in human subjects that changes in molecular weight affect the glucose response ${ }^{(28)}$, and also have different effects on gastrointestinal hormones ${ }^{(29)}$. The importance of the molecular weight of $\beta$-glucans for the cholesterol-lowering effects of oat products is not, however, completely understood. To address this, we evaluated the effects of $\mathrm{OB}$, processed to different $\mathrm{MW}_{\mathrm{p}}$ values of $\beta$-glucan $(1311,241,56,21$ and $<10 \mathrm{kDa})$, on plasma cholesterol levels, lipoprotein composition, TAG and intestinal production of SCFA in mice.

Table 3. Initial weight, body weight gain, feed intake and dry faeces for mice fed experimental diets for 4 weeks* (Mean values with their standard errors)

\begin{tabular}{|c|c|c|c|c|c|c|c|c|c|c|c|}
\hline & \multicolumn{3}{|c|}{ Intitial weight (g) } & \multicolumn{3}{|c|}{ Body weight gain (g) } & \multicolumn{3}{|c|}{$\begin{array}{c}\text { Feed intake } \\
\text { (g/mouse and } 24 \mathrm{~h})\end{array}$} & \multicolumn{2}{|c|}{$\begin{array}{l}\text { Dry faeces } \\
\text { (g/mouse } \\
\text { and } 24 \mathrm{~h} \text { ) }\end{array}$} \\
\hline & Mean & SEM & $n$ & Mean & SEM & $n$ & Mean & SEM & $n$ & Mean & $n$ \\
\hline \multicolumn{12}{|l|}{ Expt 1} \\
\hline Control & $20 \cdot 0$ & 0.3 & 10 & $1.4^{\mathrm{a}}$ & 0.3 & 10 & $2 \cdot 2^{\mathrm{a}}$ & 0.04 & $4 \dagger$ & 0.21 & $1 \dagger$ \\
\hline POB (1311 kDa) & 19.5 & 0.3 & 10 & $2 \cdot 4^{\mathrm{b}}$ & 0.2 & 10 & $2 \cdot 4^{\mathrm{a}}$ & 0.08 & $4 \dagger$ & 0.19 & $1 \dagger$ \\
\hline POB $(241 \mathrm{kDa})$ & $19 \cdot 0$ & 0.3 & 10 & $2 \cdot 6^{\mathrm{b}}$ & 0.2 & 10 & $2 \cdot 3^{\mathrm{a}}$ & 0.09 & $4 \dagger$ & 0.21 & $1 \dagger$ \\
\hline POB (56 kDa) & $19 \cdot 2$ & 0.3 & 10 & $2 \cdot 9^{b}$ & 0.3 & 10 & $2 \cdot 1^{a}$ & 0.1 & $4 \dagger$ & 0.19 & $1 \dagger$ \\
\hline POB (21 kDa) & $19 \cdot 1$ & 0.3 & 10 & $2 \cdot 4^{\mathrm{b}}$ & 0.1 & 10 & $2 \cdot 2^{a}$ & 0.09 & $4 \dagger$ & 0.19 & $1 \dagger$ \\
\hline \multicolumn{12}{|l|}{ Expt 2} \\
\hline Control & $19 \cdot 1^{\mathrm{a}}$ & 0.4 & 8 & $3 \cdot 1^{a}$ & 0.3 & 8 & $2 \cdot 3^{\mathrm{a}}$ & 0.09 & $3+$ & 0.21 & $1 \dagger$ \\
\hline OB $(2348 \mathrm{kDa}) \ddagger$ & $19 \cdot 1^{\mathrm{a}}$ & 0.2 & 10 & $5 \cdot 0^{\mathrm{b}}$ & 0.5 & 10 & $2 \cdot 4^{a}$ & 0.12 & $3+$ & 0.20 & $1 \dagger$ \\
\hline $\mathrm{POB}(<10 \mathrm{kDa})$ & $19 \cdot 2^{\mathrm{a}}$ & 0.2 & 10 & $2 \cdot 8^{\mathrm{a}}$ & 0.4 & 10 & $2 \cdot 4^{a}$ & 0.06 & $3+$ & 0.20 & $1+$ \\
\hline
\end{tabular}

$n$, Number of observations; OB, oat bran; $\mathrm{POB}$, processed $\mathrm{OB}$ with $\beta$-glucan of different peak molecular weight.

${ }_{a, b}$ Mean values with unlike superscript letters were significantly different between groups within each experiment $(P<0 \cdot 05)$.

* Statistics were calculated with one-way ANOVA for multiple comparisons (Tukey's test for pairwise comparisons of means).

$\dagger$ The number refers to the number of cages (ten mice housed per cage).

$\ddagger O B$, used as a starting material for the production of POB (see Materials and methods). 


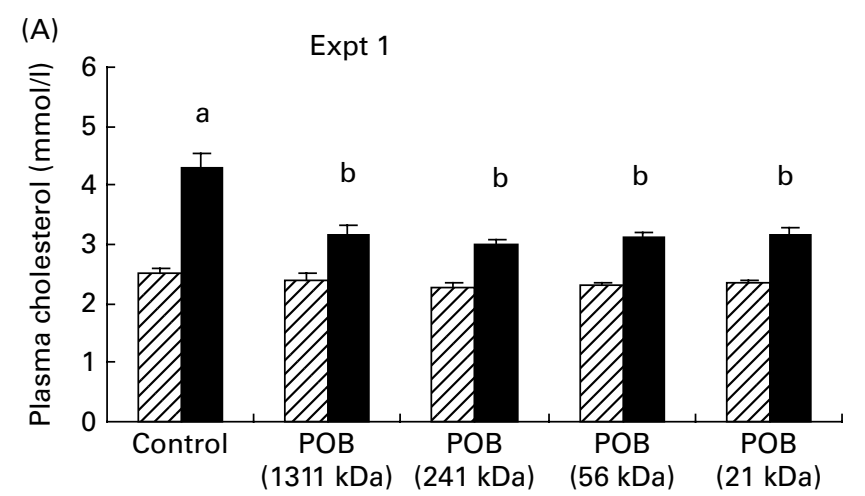

(B)

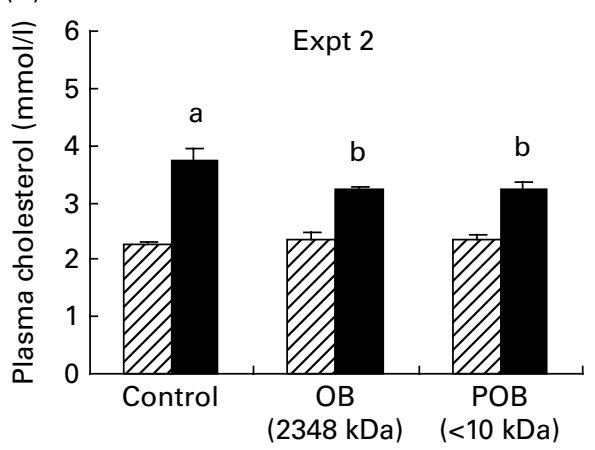

Fig. 2. Oat bran $(\mathrm{OB})$ and processed $\mathrm{OB}(\mathrm{POB})$ with $\beta$-glucans of different peak molecular weight $\left(\mathrm{MW}_{\mathrm{p}}\right)$ values reduce plasma cholesterol equally. Four POB with different $\beta$-glucan $\mathrm{MW}_{\mathrm{p}}$ values had a similar effect on plasma cholesterol ((A), $n 10)$, and a third POB with even smaller $\beta$-glucans had the same cholesterol-lowering effects as OB ((B), $n$ 8-10). Baseline values (吱) were not significantly different between the experimental groups. ${ }^{\mathrm{a}, \mathrm{b}}$ Mean values with unlike letters were significantly different $(P<0.05)$ after 4 weeks on experimental diets ( $\square$ ). Data are presented as means with their standard errors.

It should be noted that the $\mathrm{MW}_{\mathrm{p}}$ value describes the average of the molecular weight distribution of extracted $\beta$-glucans, as the curves appeared to be symmetric ${ }^{(16)}$. The $\mathrm{MW}_{\mathrm{p}}$ values for $\beta$-glucan from the two batches of $\mathrm{OB}$ used were 1800 and $2348 \mathrm{kDa}$, which is in good agreement with previously reported results ${ }^{(5,14,16)}$. The analysis used for molecular weight determination revealed that most of the $\beta$-glucans present in the sample with the lowest molecular weight had an $\mathrm{MW}_{\mathrm{p}}<10 \mathrm{kDa}$ (corresponding to less than sixty-two monomers). Interestingly, results on total dietary fibre indicated that about $50 \%$ of the dietary fibre that is present should be composed of less than ten to twenty monomers. However, we cannot exclude the possibility that cellulose fibre in addition to the $\beta$-glucans present was also digested since we used a cellulase during the production of this POB product.

The water solubility of $\beta$-glucans increased as the molecular weight decreased, and ranged from 36 to $75 \%$ for POB products (Fig. 1(A)). In comparison, $\beta$-glucans from untreated OB (dry milled) dissolved to approximately $23 \%$.

C57BL/6 mice develop high cholesterol levels when fed an atherogenic $\operatorname{diet}^{(30)}$. All the mice gained weight on experimental diets, and the molecular weight of $\beta$-glucan (from 1311 down to $21 \mathrm{kDa}$ ) had no influence on the gain in body weight. The cholesterol-lowering properties of $\mathrm{OB}$ preparations were unchanged over the whole range of $\mathrm{MW}_{\mathrm{p}}$ investigated (Fig. 2). This suggests that $\beta$-glucans with $\mathrm{MW}_{\mathrm{p}}$ as low as $10-20 \mathrm{kDa}$ are functional in lowering cholesterol, so that any limit for a loss in efficiency appears at even lower $\mathrm{MW}_{\mathrm{p}}$. We cannot, however, exclude the possibility that the cholesterol-lowering effects were partly caused by oat component(s) other than $\beta$-glucans, for example, by arabinoxylans, sterols, lipids and/or antioxidants (e.g. avenanthramides and vitamin E). The present findings regarding the effects on plasma cholesterol agree with previous studies on oat or barley $\beta$-glucans in animals ${ }^{(8,9)}$ and human subjects ${ }^{(10)}$. Furthermore, a newly published study by Bae $e t a l^{(31)}$ has shown that there is no difference in cholesterol-lowering properties between oat products with different molecular weights of $\beta$-glucan $(1450-371 \mathrm{kDa})$ in male C57BL/6 mice, which is in agreement with the results of the present study. The study by Bae et al. ${ }^{(31)}$ used enriched $\beta$-glucan at a high concentration $(8.6 \%)$, which is hardly attainable in human diets and which may have influenced the nutritional state, as the animals differed significantly in weight gain between the experimental groups.

In the present study, the viscous properties of the five POB were found to vary with $\mathrm{MW}_{\mathrm{p}}$ of the $\beta$-glucans (Fig. 1(C)). One hypothesis might be that these samples create different viscosities of the absorptive layer in the small intestine, and consequently affect the absorption rate as well as the amount of cholesterol absorbed into the plasma differently. We found, however, no correlation between plasma cholesterol levels and the viscous properties of POB. Thus, other mechanisms for the cholesterol-lowering effects must be considered (e.g. intestinal fermentation). Even so, we cannot exclude the possibility that $\beta$-glucans increase the viscosity of the intestinal contents in a way that is not strongly dependent on molecular weight or on the viscous properties of the $\beta$-glucans themselves. It has, for example, been suggested

Table 4. LDL + VLDL levels in mice at baseline and after 4 weeks on experimental diets*

(Mean values with their standard errors)

\begin{tabular}{|c|c|c|c|c|c|}
\hline & \multicolumn{5}{|c|}{ LDL + VLDL (\%)† } \\
\hline & \multicolumn{2}{|c|}{ Baseline } & \multicolumn{2}{|c|}{4 Weeks } & \multirow[b]{2}{*}{$n$} \\
\hline & Mean & SEM & Mean & SEM & \\
\hline \multicolumn{6}{|l|}{ Expt 1} \\
\hline Control & $28 \cdot 7^{\mathrm{a}}$ & $2 \cdot 5$ & $60 \cdot 4^{a}$ & 1.4 & 10 \\
\hline POB (1311 kDa) & $21 \cdot 7^{\mathrm{a}}$ & 1.9 & $53 \cdot 4^{\mathrm{a}}$ & 2.5 & 10 \\
\hline POB $(241 \mathrm{kDa})$ & $25 \cdot 8^{\mathrm{a}}$ & $2 \cdot 2$ & $52 \cdot 9^{\mathrm{a}}$ & 1.9 & 10 \\
\hline POB (56 kDa) & $22 \cdot 0^{\mathrm{a}}$ & 1.8 & $59 \cdot 4^{\mathrm{a}}$ & $2 \cdot 8$ & 10 \\
\hline POB (21 kDa) & $22 \cdot 6^{a}$ & 1.9 & $58 \cdot 9^{a}$ & $2 \cdot 7$ & 10 \\
\hline \multicolumn{6}{|l|}{ Expt 2} \\
\hline Control & $22 \cdot 7^{a}$ & $2 \cdot 4$ & $57.9^{a}$ & 5.9 & 8 \\
\hline OB $(2348 \mathrm{kDa}) \ddagger$ & $26 \cdot 4^{\mathrm{a}}$ & $2 \cdot 0$ & $42 \cdot 9^{\mathrm{a}}$ & 4.9 & 10 \\
\hline $\mathrm{POB}(<10 \mathrm{kDa})$ & $24.5^{\mathrm{a}}$ & 1.3 & $54 \cdot 2^{\mathrm{a}}$ & $2 \cdot 0$ & 10 \\
\hline
\end{tabular}

$n$, Number of observations; $\mathrm{POB}$, processed $\mathrm{OB}$ with $\beta$-glucan of different peak molecular weights; $\mathrm{OB}$, oat bran.

${ }^{a}$ Mean values within a column with superscript letter was significantly different between groups within each experiment $(P<0.05)$.

* Statistical analysis was performed by using one-way ANOVA for multiple comparisons (Tukey's test for pairwise comparisons of means $P<0.05$ ) on normally distributed data.

†Calculated as $(\mathrm{LDL}+\mathrm{VLDL}) /(\mathrm{HDL}+\mathrm{LDL}+\mathrm{VLDL}) \times 100$.

$\ddagger O B$, used as a starting material for the production of $\mathrm{POB}$ (see Materials and methods). 
that increased viscosity of the intestinal contents may be an effect of increased mucus secretion stimulated by the presence of $\beta$-glucans. This hypothesis was based on the finding that the small intestinal content was viscous even after a $13-\mathrm{h}$ fasting period, when no $\beta$-glucans were detected in the material from the small intestine ${ }^{(32)}$.

The difference in $\mathrm{MW}_{\mathrm{p}}$ of $\beta$-glucan in the different $\mathrm{OB}$ preparations had no statistically significant influence on the measured proportions of LDL + VLDL and HDL (Table 4). The electrophoretic separation of plasma lipoproteins is evaluated by staining of all plasma lipids (cholesterol, TAG and phospholipids) in the bands, and possible changes in HDL $v$. non-HDL cholesterol may therefore be obscured by the contributions from other lipids. In our previous study, the OB group had significantly lower LDL + VLDL values than the control group ${ }^{(14)}$.

$\beta$-Glucans generally belong to the group of indigestible carbohydrates, which includes NSP, resistant starch and oligosaccharides. These are not digested and absorbed in the small intestine, but are partially or completely fermented to SCFA in the large intestine. However, animal studies have shown that the molecular weight of $\beta$-glucans is reduced during passage through the upper gastrointestinal tract, reaching between 35 and $100 \mathrm{kDa}$ in the small intestinal content of pigs ${ }^{(33)}$, hamsters ${ }^{(8)}$ and rats ${ }^{(34)}$, which suggests that the molecular weight of $\beta$-glucans may have been reduced during passage through the gastrointestinal tract in the present study also.

$\beta$-Glucans are generally considered to be water-soluble, fermentable dietary fibre. In contrast, cellulose is a waterinsoluble fibre and is much more resistant to fermentation, giving low amounts of $\mathrm{SCFA}^{(35)}$. The effects on colonic fermentation of four POB products, containing $\beta$-glucans with different $\mathrm{MW}_{\mathrm{p}}(1311,241,56$ or $21 \mathrm{kDa})$, were evaluated in Expt 1 (Table 5). The major fatty acids formed were acetic acid, propionic acid and butyric acid at a mean ratio of $64: 23: 13$. This is in the same range as the ratios found in studies on human intestinal material ${ }^{(36,37)}(57: 22: 21)$ and on rat caecum ${ }^{(35)}(69: 21: 10)$.

Butyric acid is usually considered to be important for the health of the colon, and a high degree of butyric acid formation has recently been suggested to have metabolic effects $^{(38-40)}$. Drzikova et $a l .^{(41)}$ found that the caecal pool of propionate and butyrate was significantly higher in rats fed an OB-based diet than in those fed a cellulose-containing diet, as we also obtained for the POB product with the highest $\mathrm{MW}_{\mathrm{p}}$ of $\beta$-glucans.

Propionic acid has previously been suggested to reduce plasma cholesterol levels in human subjects, but the mechanism behind this is not completely understood ${ }^{(13,42-44)}$. The acetate produced after fermentation of fibres in the intestine is readily absorbed and transported to the liver where it can act as a substrate for acetyl-CoA formation, the precursor for endogenous cholesterol synthesis. It has been suggested that propionate could possibly impair the acetate utilisation, and thereby also cholesterol biosynthesis ${ }^{(42,45,46)}$. In the present study, we found that all POB gave rise to significantly higher pools of propionic acid compared with the control diet. There was no clear effect of $\beta$-glucan $\mathrm{MW}_{\mathrm{p}}$ on the pools of either propionic acid or acetic acid and, except for the lowest $\mathrm{MW}_{\mathrm{p}}$, the ratio between propionic acid and acetic acid was significantly higher for all POB groups 
Table 6. Ratio between the major caecal SCFA formed in mice (Expt 1) ${ }^{\star}$ (Mean values with their standard errors)

\begin{tabular}{llllllr}
\hline & \multicolumn{2}{c}{$\begin{array}{c}\text { (PRO }+ \\
\text { BUT)/ACE }\end{array}$} & & \multicolumn{2}{c}{ PRO/ACE } \\
\cline { 2 - 3 } Dietary group/ratio & Mean & SEM & & Mean & SEM & $n$ \\
\hline Control & $0.40^{\mathrm{a}}$ & 0.02 & & $0.28^{\mathrm{a}}$ & 0.02 & 10 \\
POB (1311 kDa) & $0.73^{\mathrm{b}}$ & 0.05 & & $0.40^{\mathrm{b}}$ & 0.02 & 9 \\
POB (241 kDa) & $0.65^{\mathrm{b}, \mathrm{c}}$ & 0.04 & & $0.42^{\mathrm{b}}$ & 0.03 & 8 \\
POB (56 kDa) & $0.54^{\mathrm{c}}$ & 0.03 & & $0.39^{\mathrm{b}}$ & 0.02 & 9 \\
POB (21 kDa) & $0.54^{\mathrm{c}}$ & 0.02 & & $0.34^{\mathrm{a}, \mathrm{b}}$ & 0.02 & 10 \\
\hline
\end{tabular}

PRO, propionic acid; BUT, butyric acid; ACE, acetic acid; $n$, number of observations; $\mathrm{POB}$, processed oat bran with $\beta$-glucan of different peak molecular weights.

${ }^{\text {a,b.c }}$ Mean values within a column with unlike superscript letters indicate statistical significant difference between groups $(P<0 \cdot 05)$.

* Statistical analysis was performed by using one-way ANOVA for multiple comparisons (Tukey's test for pairwise comparisons of means $P<0.05$ ) on normally distributed data.

$v$. control group. There was, however, a significant positive correlation between the ratio of (propionic acid + butyric acid)/acetic acid and the $\mathrm{MW}_{\mathrm{p}}$ of $\beta$-glucans (Table 6). Since this SCFA ratio was dependent on the $\mathrm{MW}_{\mathrm{p}}$ of $\beta$-glucan but the plasma cholesterol was not, we suggest that caecal formation of specific SCFA may not have been a crucial mechanism for the cholesterol-lowering effects of oats found in the mice. However, it cannot be excluded that the results of SCFA in plasma would have been different.

The caecal content was significantly higher for mice fed $\beta$-glucans of the highest molecular weight than for those fed a cellulose-based control diet, which is in agreement with a previous study on rats fed a diet based on $\mathrm{OB}^{(41)}$. The weight of caecal tissue was, however, significantly higher in mice fed low-MW $\mathrm{M}_{\mathrm{p}}$ oat products. This might be due to an extensive fermentation of $\beta$-glucans and utilisation of SCFA. Another potential explanation is that the formation of SCFA is involved in the proposed stimulation of mucus secretion by $\beta$-glucans ${ }^{(32,47)}$.

The results of the present study suggest that the molecular weight of $\beta$-glucan and the viscosity of oat products may not be crucial parameters for the cholesterol-lowering effects. However, this does not preclude the possibility that the viscosity of the intestinal contents may be of importance through a more complex mechanism, and that this may be affected by $\beta$-glucans without there being any strong relationship concerning the viscosity of $\beta$-glucans themselves. Binding of bile acids to $\beta$-glucans is another possible mechanism of action that may not be strongly dependent on molecular weight. Regarding the formation of SCFA in the caecum, we found that all POB gave rise to a significantly higher caecal content of propionic acid compared with the control group. There was no clear relationship between $\mathrm{MW}_{\mathrm{p}}$ and propionic acid content, but the ratio of (propionic acid + butyric acid)/ acetic acid increased with increasing $\mathrm{MW}_{\mathrm{p}}$ of $\beta$-glucans.

The cholesterol-lowering effects of oats are most likely a result of different mechanisms, and the present study indicates that development of new oat-based products with beneficial health effects can involve incorporation of $\beta$-glucans with a wide range of molecular sizes. However, human trials are needed to confirm the validity of the conclusions drawn from the present study. It would be interesting to define more exactly how individual oat components, such as $\beta$-glucans, sterols and various antioxidants, contribute to the cholesterol-lowering effects.

\section{Acknowledgements}

The present study was supported by the Functional Food Science Centre at Lund University and by OATLY AB. T. I. was responsible for the preparation and analysis of $\mathrm{OB}$ products, production and documentation of diets, analysis of caecal tissue and caecal content, statistical evaluation of all data, and for writing the manuscript. K. E. A. was responsible for the animal studies and plasma lipid analyses. A. R. was responsible for the $\mathrm{POB}$ processes. C. W. was responsible for the production of liquid oat suspensions at OATLY AB, and for the analysis of sugar content of POB products, and participated in diet preparation and animal experiments. All authors took part in planning of the experiments and contributed to evaluation of the results and writing of the manuscript. We thank Cathy Wang (Guelph Food Research Centre, Guelph, Canada) for analysing the $\mathrm{MW}_{\mathrm{p}}$ of $\beta$-glucan, Christer Fahlgren (Applied Nutrition and Food Chemistry, Lund University, Lund, Sweden) for analysis of caecal SCFA and Ina Nordström (Department of Experimental Medical Science, Lund University, Lund, Sweden) for analysis of blood lipids. The authors declare no conflict of interest.

\section{References}

1. Braaten JT, Wood P, Scott FW, et al. (1994) Oat beta-glucan reduces blood cholesterol concentration in hypercholestererolemic subjects. Eur J Clin Nutr 48, 465-474.

2. US Food Drug Administration (1997) FDA final rule for federal labelling: health claims, oats and coronary heart disease. Fed Regist 62, 3584-3681.

3. U.S. Food and Administration and FDA Events \& News (2006) FDA finalizes health claim associating consumption of barley products with reduction of risk of coronary heart disease, pp. 06-70. http://www.fda.gov/NewsEvents/Newsroom/Press Announcements/2006/ucm108657.htm (assessed October 2009).

4. Cui SW \& Wood PJ (2000) Relationships between structural features, molecular weight and rheological properties of cereal $\beta$-D-glucans. In Hydrocolloids: Physical Chemistry and Industrial Applications of Gels, Polysaccharides and Proteins, pp. 159-168 [K Nishinari, editor]. London: Elsevier Science Publishers.

5. Åman P, Rimsten L \& Andersson R (2004) Molecular weight distribution of beta-glucan in oat-based foods. Cereal Chem 81, 356-360.

6. Lan-Pidhainy X, Brummer Y, Tosh SM, et al. (2007) Reducing beta-glucan solubility in oat bran muffins by freeze-thaw treatment attenuates its hypoglycemic effect. Cereal Chem $\mathbf{8 4}$, 512-517.

7. Wood P, Braaten JT, Scott FW, et al. (1994) Effect of dose and modification of viscous properties of oat gum on plasma glucose and insulin following an oral glucose load. Br J Nutr 72, $731-743$.

8. Yokoyama WH, Knuckles BE, Wood D, et al. (2002) Food processing reduces size of soluble cereal beta-glucan polymers without loss of cholesterol-reducing properties. In Bioactive Compounds in Foods - Effects of Processing and Storage, pp. 105-116. ACS Symposium Series 816 [TC Lee and CT Ho, editors]. Washington, DC: American Chemical Society. 
9. Wilson TA, Nicolsi RJ, Delaney B, et al. (2004) Reduced and high molecular weight barley beta-glucans decrease plasma total and non-HDL-cholesterol in hypercholesterolemic Syrian golden hamsters. J Nutr 134, 2617-2622.

10. Keenan JM, Goulson M, Shamliyan T, et al. (2007) The effects of concentrated barley beta-glucan on blood lipids in a population of hypercholesterolaemic men and women. $\mathrm{Br} J$ Nutr 97, 1162-1168.

11. Gallaher DD, Hassel CA \& Lee K-J (1993) Relationships between viscosity of hydroxypropylmethylcellulose and plasma cholesterol in hamsters. J Nutr 123, 1732-1738.

12. Lund EK, Gee JM, Brown JC, et al. (1989) Effect of oat gum on the physical properties of the gastrointestinal contents and on the uptake of D-galactose and cholesterol by rat small intestine in vitro. Br J Nutr 62, 91-101.

13. Levrat MA, Favier ML, Moundras C, et al. (1994) Role of dietary propionic acid and bile acid excretion in the hypocholesterolemic effects of oligosaccharides in rats. $J$ Nutr 124, 531-538.

14. Andersson KE, Immerstrand T, Swärd K, et al. (2010) Effects of oats on plasma cholesterol and lipoproteins in C57BL/6 mice are substrain-specific. Br J Nutr 103, 513-521.

15. Triantafyllou Oste A (2001) Enzyme preparations for modifying cereal suspensions. United States patent. US 6190708 B1.

16. Immerstrand $\mathrm{T}$, Bergenståhl $\mathrm{B}$, Trägårdh $\mathrm{C}$, et al. (2009) Extraction of $\beta$-glucan from oat bran in laboratory scale. Cereal Chem 86, 601-608.

17. McCleary BV \& Codd R (1991) Measurement of $(1 \rightarrow 3)(1 \rightarrow 4)-\beta$-D-glucan in barley and oats: a streamlined enzymatic procedure. J Sci Food Agric 55, 303-312.

18. Schmid W (1888) Bestimmung des Fetthaltes in Milch (Determination of fat in milk) Zeitschrift für Analytische Chemie 27, 464.

19. Bondzynski S (1889) Über die von Werner Schmid vorgeschlagene Methode der des Fettbestimmung in der Milch (About the method proposed by Werner Schmid for the determination of fat in the milk). Landwirth Jahrbuch der Schweiz 3, 119-121.

20. Ratzlaff E (1903) Über die Brauchbarkiet der verschiedenen Fettbestimmungsmethoden im Käse (About the utility of different methods for determination of fat in cheese). Milch-Zeitung 32, 65-67.

21. Prosky L, Asp N-G, Furda I, et al. (1985) Determination of total dietary fiber in foods and food products: collaborative study. J Assoc Off Anal Chem 68, 677-679.

22. Asp N-G, Johansson C-G, Hallmer H, et al. (1983) Rapid enzymatic assay of insoluble and soluble dietary fibre. J Agric Food Chem 31, 476-482.

23. Spiller GA (2000) Enzymatic gravimetric methods. In Handbook of Dietary Fiber in Human Nutrition, 2nd ed., pp. 37-48 [GA Spiller, editor]. Boca Raton, FL: CRC Press.

24. Noble RP (1968) Electrophoretic separation of plasma lipoproteins in agarose gel. J Lipid Res 9, 693-700.

25. Zhou G, Nyman M \& Jönsson JÅ (2006) Rapid determination of short-chain fatty acids in colonic contents and faeces of humans and rats by acidified water-extraction and direct-injection gas chromatography. Biomed Chromatogr 20, 674-682.

26. Siegel S \& Castellan NJ Jr (1988) The Kruskal-Wallis one way analysis of variance by ranks. In Nonparametric Statistics for the Behavioural Sciences, pp. 206-214 [JD Anker, editor]. New York: McGraw-Hill Book Company, Inc.

27. Gomez C, Navarro A, Carbonell JV, et al. (2000) Determination of the apparent molecular weight cut-off for the fluorometric calcofluor-FIA method when detecting $(1 \rightarrow 3)(1 \rightarrow 4)-\beta$-D-glucan using a high ionic strength eluant. J Cereal Sci 31, 155-157.
28. Wood PJ, Beer MU \& Butler G (2000) Evaluation of role of concentration and molecular weight of oat betaglucan in determining effect of viscosity on plasma glucose and insulin following an oral glucose load. Br J Nutr 84, 19-23.

29. Juvonen KR, Purhonen A-K, Salmenkallio-Marttila M, et al. (2009) Viscosity of oat bran-enriched beverages influences gastrointestinal hormonal responses in healthy humans. J Nutr 139, 461-466.

30. Paigen B, Mitchell D, Reue K, et al. (1987) Ath-1, a gene determining atherosclerosis susceptibility and high density lipoprotein levels in mice. Proc Natl Acad Sci U S A 84, 3763-3767.

31. Bae Y, Lee S, Kim SM, et al. (2009) Effect of partially hydrolyzed oat beta-glucan on the weight gain and lipid profile of mice. Food Hydrocolloids 23, 2016-2021.

32. Bégin F, Vachon C, Jones JD, et al. (1989) Effect of dietary fibers on glycemia and insulenemia and on gastrointestinal function in rats. Can J Physiol Pharmacol 67, 1265-1271.

33. Johansen HN \& Knudsen KEB (1997) Physico-chemical properties and the degradation of oat bran polysaccharides in the gut of pigs. $J$ Sci Food Agric 73, 81-92.

34. Wood PJ, Weisz J \& Mahn W (1991) Molecular characterization of cereal beta-glucans. II. Size-exclusion chromatography for comparison of molecular weight. Cereal Chem 68, 530-536.

35. Berggren AM, Björk IME, Nyman EMG, et al. (1993) Short-chain fatty acid content and $\mathrm{pH}$ in caecum of rats given various sources of carbohydrates. J Sci Food Agric 63, 397-406.

36. Cummings JH, Pomare EW, Branch WJ, et al. (1987) Short chain fatty acids in human large intestine, portal, hepatic and venous blood. Gut 28, 1221-1227.

37. Macfarlane S \& Macfarlane GT (2003) Regulation of shortchain fatty acid production. Proc Nutr Soc 62, 67-72.

38. Marcil V, Delvin E, Seidman E, et al. (2002) Modulation of lipid synthesis, apolipoprotein biogenesis, and lipoprotein assembly by butyrate. Am J Physiol Gastrointest Liver Physiol 283, G340-G346.

39. Marcil V, Delvin E, Garofalo C, et al. (2003) Butyrate impairs lipid transport by inhibiting microsomal triglyceride transfer protein in Caco-2-cells. J Nutr 133, 2180-2183.

40. Galisteo M, Duarte J \& Zarzuelo A (2008) Effects of dietary fibers on disturbances clustered in the metabolic syndrome. J Nutr Biochem 19, 71-84.

41. Drzikova B, Dongowski G \& Gebhardt E (2005) Dietary fibre-rich oat-based products affect serum lipids, microbiota, formation of SCFA and steroids in rats. Br J Nutr 94, 1012-1025.

42. Wolever TM, Spadafora P \& Eshuis H (1991) Interaction between colonic acetate and propionate in humans. Am J Clin Nutr 53, 681-687.

43. Lin Y, Vonk RJ, Slooff MJH, et al. (1995) Differences in propionate-induced inhibition of cholesterol and TAG synthesis between human and rat hepatocytes in primary culture. $\mathrm{Br} J$ Nutr 74, 197-207.

44. Wolever TM, Fernandes J \& Rao AV (1996) Serum acetate: propionate ratio is related to serum cholesterol in men but not women. J Nutr 126, 2790-2797.

45. Demigné C, Morand C, Levrat MA, et al. (1995) Effect of propionate on fatty acid and cholesterol synthesis and on acetate metabolism in isolated rat hepatocytes. $\mathrm{Br} J \mathrm{Nutr} \mathbf{7 4}$, 209-219.

46. Delzenne NM \& Williams CM (2002) Prebiotics and lipid metabolism. Curr Opin Lipidol 13, 61-67.

47. Finnie IA, Dwarakanath AD, Taylor BA, et al. (1995) Colonic mucin synthesis is increased by sodium butyrate. Gut 36, 93-99. 